\title{
Set of Time Series Forecasting Models Using the Ordered Difference
}

\author{
Hongxu Wang ${ }^{1}$, Chengguo Yin ${ }^{2, *}$, Xiaoli Lu ${ }^{1}$, Hao Feng ${ }^{3}$ and Xiaofang $\mathrm{Fu}^{2}$ \\ ${ }^{1}$ School of Ocean Business, Hainan Tropical Ocean University, Sanya, Hainan, China \\ ${ }^{2}$ School of Ocean Information Engineering, Hainan Tropical Ocean University, Sanya, Hainan, China \\ ${ }^{3}$ School of Ocean Science and Technology, Hainan Tropical Ocean University, Sanya, Hainan, China \\ ${ }^{*}$ Corresponding author
}

\begin{abstract}
Set of time series forecasting models using the ordered difference of historical data (SOD) is proposed. For a time series, for example, for the enrollment of the University of Alabama in 1971-1992, when simulating the prediction of historical data, the automatic optimization search method can be used to sieve the satisfactory time series forecasting model $F_{w}(0.00003,0.00003)$ in SOD, and the average forecasting error rate (AFER) of the predicted values can reach $A F E R=0 \%$ and the mean square error (MSE) is MSE=0. The problem that the prediction accuracy of the existing fuzzy time series forecasting models is not high has been solved.
\end{abstract}

Keywords-the fractional sum function $D_{w}(x, y)$ of SOD; the inverse function $E_{w}(x, y)$ of fractional sum function of SOD; the forecasting model $F_{w}(x, y)$ of SOD; automatic optimization search method; time series

\section{INTRODUCTION}

Time series analysis is an old problem, the research on time series can be traced back to the paper proposed by Yule in 1927 [1]. In that paper, he carried out time series analysis on the Wolfer's sunspot numbers of 1749-1924, he found that sunspot numbers would come to a maximum every 9 to 11 years. The sunspots studied by Yule [1] are time series, which are the time series with no regularity. In the past ninety years, with the continuous progress of mathematical theory and computational technique, the classical models and methods have been fully able to study and deal with regular time series.

For the time series problem with regularity, Song and Chissom [2,3] (1993) first applied fuzzy set theory [5] to study them; the famous case is: the enrollment of the University of Alabama in 1971-1992, the historical data are shown in TABLE I [2-4], and the distribution diagram is shown in FIGURE I. This is a typical time series without any rules. Up to now, although many scholars have proposed the fuzzy time series forecasting models (for example, the forecasting models proposed in [7-14]) to simulate the prediction of the enrollment of the University of Alabama in 1971-1992, the AFER and MSE of the predicted value of the enrollment are still large.

It has some practical significance to simulate the prediction of historical data of time series. For example, it can be used to study stock [8]; studying traffic accidents can be useful for studying the amount of car premiums [6], etc. This article is enlightened by the paper of Jilani, Burney, and Ardil [6,7], set of time series forecasting models using the ordered difference of historical data (SOD) is proposed. The concept of satisfactory time series forecasting model is proposed, and the automatic optimization search method is presented. For the enrollment of the University of Alabama in 1971-1992, the automatic optimization search method can be used to sieve the time series forecasting model $F_{w}(0.00003,0.00003)$, the average forecasting error rate (AFER) of the predicted value of the enrollment is AFER $=0 \%$ and the mean square error (MSE) is $\mathrm{MSE}=0$. The problem that the prediction accuracy of the existing fuzzy time series forecasting models is not high has been solved.

\section{SET OF Time Series ForecAsting MOdELs (SOD)}

Definition 1. If the universe of discourse of historical data of a time series is $A=\left\{A_{1}, A_{2}, \ldots, A_{n}\right\}$. The calculation formula of the difference of historical data is $B_{w}=A_{w}-A_{w-1}$. The data in the universe of discourse $B=\left\{B_{2}, B_{3}, \ldots, B_{n}\right\}$ of the difference of historical data are arranged from small to large, then constitute a new set $b=\left\{b_{2}, b_{3}, \ldots, b_{n}\right\}$, which is called the universe of discourse of the ordered difference of historical data.

Definition 2. If the universe of discourse of historical data of a time series is $A=\left\{A_{1}, A_{2}, \ldots, A_{n}\right\}$, the universe of discourse of the difference of historical data is $B=\left\{B_{2}, B_{3}, \ldots\right.$, $\left.B_{n}\right\}$, the universe of discourse of the ordered difference of historical data is $b=\left\{b_{2}, b_{3}, \ldots b_{n}\right\},(1)$, (2), and (3) are defined on $b$, where the independent variables $x \in(0,1)$ and $y \in(0,1)$. $D_{w}(x, y)$ is the fractional sum function of SOD; $E_{w}(x, y)$ is the corresponding inverse function of fractional sum function $\mathrm{D}_{\mathrm{w}}(\mathrm{x}, \mathrm{y}) ; \mathrm{F}_{\mathrm{w}}(\mathrm{x}, \mathrm{y})$ is the forecasting function of SOD.

$$
D_{w}(x, y)= \begin{cases}\frac{1}{b_{2}}+\frac{y}{b_{3}}, & w=2, \\ \frac{x}{b_{w-1}}+\frac{1}{b_{w}}+\frac{y}{b_{w+1}}, & 3 \leq w \leq n-1, \\ \frac{x}{b_{n-1}}+\frac{1}{b_{n}}, & w=n .\end{cases}
$$




$$
\begin{aligned}
& E_{w}(x, y)= \begin{cases}\frac{1+y}{\frac{1}{b_{2}}+\frac{y}{b_{3}}}, & w=2, \\
\frac{x+1+y}{\frac{x}{b_{w-1}}+\frac{1}{b_{w}}+\frac{y}{b_{w+1}}} & , 3 \leq w \leq n-1, \\
\frac{x+1}{\frac{x}{b_{n-1}}+\frac{1}{b_{n}}}, & w=n .\end{cases} \\
& F_{w}(x, y)=A_{w-1}+E_{w}(x, y) .
\end{aligned}
$$

Definition 3. Arbitrarily taking a $\mathrm{x} \in(0,1)$ and $\mathrm{y} \in(0,1)$, we can obtain a time series forecasting model. A set of all such forecasting models constructs: the set of time series forecasting models using the ordered difference (STSFMUOD), the abbreviation is further simplified as SOD.

Definition 4. For a time series, if the prediction of the historical data of the time series is simulated, and the predicted values obtain $\mathrm{MSE}=0$ and $\mathrm{AFER}=0 \%$, then the time series forecasting model is called satisfactory.

Definition 5. For a time series, the satisfactory time series forecasting model in SOD is automatically searched, this method is called automatic optimization search method. The detailed approach is: for a time series, a decimal number is used as the starting point, programming, searching, and computing, ..., until the satisfactory time series forecasting model in SOD is sieved (satisfy AFER $=0 \%$ ).

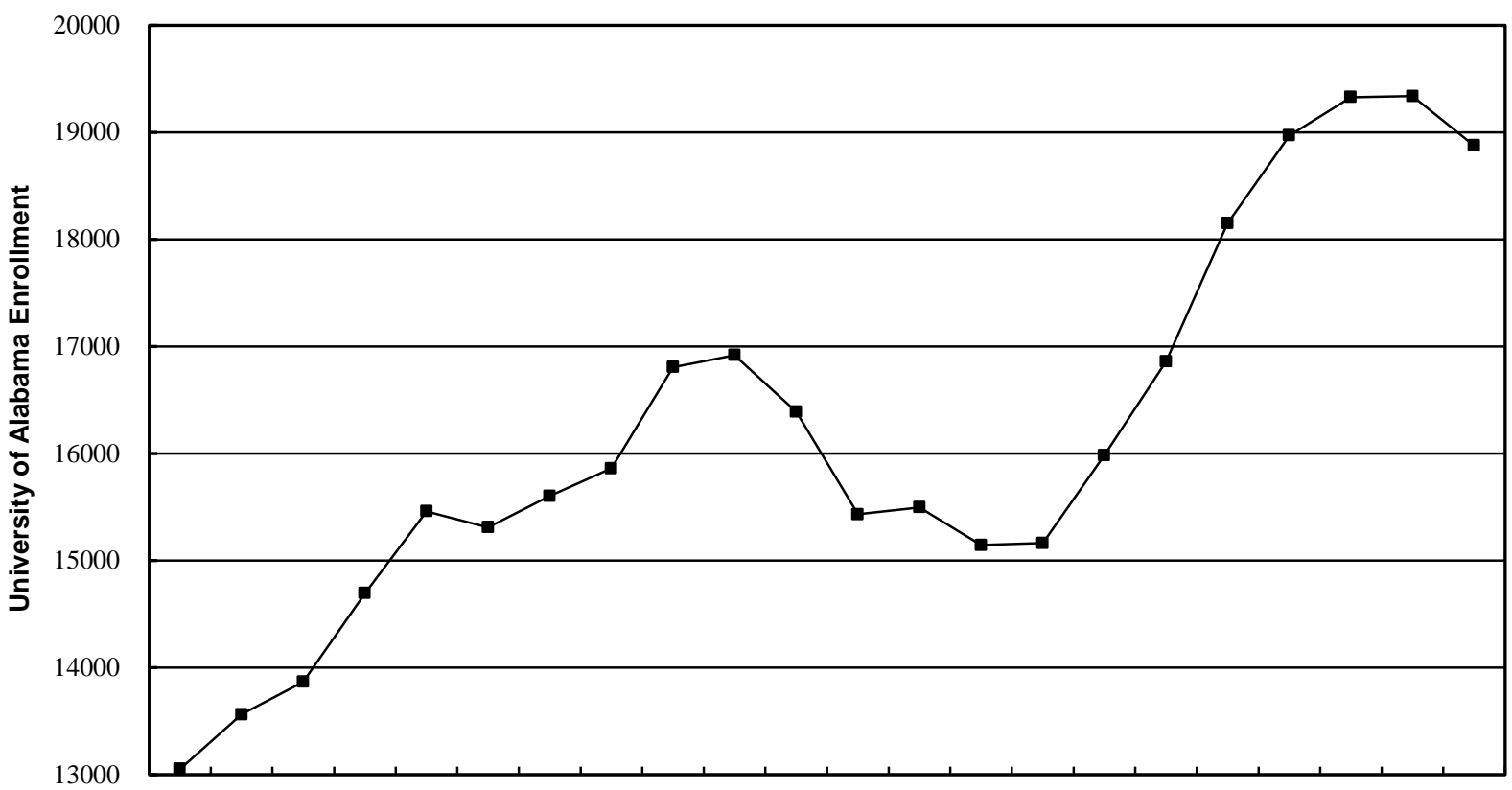

1971197219731974197519761977197819791980198119821983198419851986198719881989199019911992

Year

FIGURE I. THE DISTRIBUTION DIAGRAM OF THE ENROLLMENT OF THE UNIVERSITY OF ALABAMA IN 1971-1992.

Example 1.In simulating the prediction of the enrollment of the University of Alabama in 1971-1992, the whole process of applying automatic optimization search method to sieve the satisfactory time series forecasting model in SOD is: 1) Input the universe of discourse A of historical data of the time series, the universe of discourse $\mathrm{B}$ of the difference, and the universe of discourse $b$ of the ordered difference. 2) Using $x=y=0.003$ as starting point, successively select $\mathrm{x}=\mathrm{y}=0.003, \mathrm{x}=\mathrm{y}=$ $0.0003, \mathrm{x}=\mathrm{y}=0.00003, \ldots$, through programming, searching, and computing, ..., until the satisfactory time series forecasting model is sieved. We first get TABLE I, because AFER $\neq 0 \%$ and MSE $\neq 0$, continue searching, calculating, then get TABLE II; because AFER $\neq 0 \%$ and MSE $\neq 0$, continue searching, calculating, then get TABLE III; because AFER $=0 \%$ and MSE $=0, \mathrm{~F}_{\mathrm{w}}(0.00003,0.00003)$ in TABLE III is a satisfactory time series forecasting model.

\section{CONCLUSIONS}

For a time series, the automatic optimization search method can be used to sieve ideal and satisfactory time series forecasting model in SOD, in such a fashion that the prediction accuracy of predicted values can reach AFER $=0 \%$ and MSE $=0$. The problem that the prediction accuracy of the existing fuzzy time series forecasting models is not high has been solved. Such time series forecasting model also has certain practical significance. 
TABLE I. PARTIAL FORECASTING MODEL OF F $\mathrm{F}_{\mathrm{W}}(0.003,0.003)$ IS APPLIED TO FORECAST THE ENROLLMENT OF THE UNIVERSITY OF ALABAMA

\begin{tabular}{|c|c|c|c|c|c|c|}
\hline Year & $\begin{array}{c}\text { Enrollment } \\
\mathbf{A}_{\mathbf{u w}} \\
\end{array}$ & $\begin{array}{l}\text { The ordered difference } \\
b_{w}\end{array}$ & $\begin{array}{c}\text { Forecast } \\
\text { F }_{\text {uw }} \\
\end{array}$ & $\mathbf{F}_{\mathbf{u w}}-\mathbf{A}_{\mathbf{u w}}$ & $\left(\mathbf{F}_{\mathrm{uw}}-\mathbf{A}_{\mathrm{uw}}\right)^{2}$ & $\left|\mathbf{F}_{\mathbf{u w}}-\mathbf{A}_{\mathbf{u w}}\right| / \mathbf{A}_{\mathbf{u w}}$ \\
\hline 1971 & 13055 & - & - & - & - & - \\
\hline 1972 & 13563 & $\mathrm{~d}_{1}, \mathrm{C}_{1982,},-955$ & 13563 & 0 & 0 & 0.000000 \\
\hline 1973 & 13867 & $\mathrm{~d}_{2}, \mathrm{C}_{1981},-531$ & 13867 & 0 & 0 & 0.000000 \\
\hline 1974 & 14696 & $\mathrm{~d}_{3}, \mathrm{C}_{1992},-461$ & 14696 & 0 & 0 & 0.000000 \\
\hline 1975 & 15460 & $\mathrm{~d}_{4}, \mathrm{C}_{1984},-352$ & 15459 & -1 & 1 & 0.000065 \\
\hline 1976 & 15311 & $\mathrm{~d}_{5}, \mathrm{C}_{1976},-149$ & 15302 & -9 & 81 & 0.000588 \\
\hline 1977 & 15603 & $\mathrm{~d}_{6}, \mathrm{C}_{1991}, 9$ & 15603 & 0 & 0 & 0.000000 \\
\hline 1978 & 15861 & $\mathrm{~d}_{7}, \mathrm{C}_{1985}, 18$ & 15860 & -1 & 1 & 0.000063 \\
\hline 1979 & 16807 & $\mathrm{~d}_{8}, \mathrm{C}_{1983}, 64$ & 16808 & 1 & 1 & 0.000059 \\
\hline 1980 & 16919 & $\mathrm{~d}_{9}, \mathrm{C}_{1980}, 112$ & 16919 & 0 & 0 & 0.000000 \\
\hline 1981 & 16388 & $\mathrm{~d}_{10}, \mathrm{C}_{1978}, 258$ & 16388 & 0 & 0 & 0.000000 \\
\hline 1982 & 15433 & $\mathrm{~d}_{11}, \mathrm{C}_{1977}, 292$ & 15435 & 2 & 4 & 0.000130 \\
\hline 1983 & 15497 & $\mathrm{~d}_{12}, \mathrm{C}_{1973}, 304$ & 15497 & 0 & 0 & 0.000000 \\
\hline 1984 & 15145 & $\mathrm{~d}_{13}, \mathrm{C}_{1990}, 358$ & 15146 & 1 & 1 & 0.000066 \\
\hline 1985 & 15163 & $\mathrm{~d}_{14}, \mathrm{C}_{1972}, 508$ & 15163 & 0 & 0 & 0.000000 \\
\hline 1986 & 15984 & $\mathrm{~d}_{15}, \mathrm{C}_{1975}, 764$ & 15984 & 0 & 0 & 0.000000 \\
\hline 1987 & 16859 & $\mathrm{~d}_{16}, \mathrm{C}_{1989}, 820$ & 16859 & 0 & 0 & 0.000000 \\
\hline 1988 & 18150 & $\mathrm{~d}_{17}, \mathrm{C}_{1986}, 821$ & 18149 & -1 & 1 & 0.000055 \\
\hline 1989 & 18970 & $\mathrm{~d}_{18}, \mathrm{C}_{1974}, 829$ & 18970 & 0 & 0 & 0.000000 \\
\hline 1990 & 19328 & $\mathrm{~d}_{19}, \mathrm{C}_{1987}, 875$ & 19328 & 0 & 0 & 0.000000 \\
\hline 1991 & 19337 & $\mathrm{~d}_{20}, \mathrm{C}_{1979}, 946$ & 19337 & 0 & 0 & 0.000000 \\
\hline 1992 & 18876 & $\mathrm{~d}_{21}, \mathrm{C}_{1988}, 1291$ & 18876 & 0 & 0 & 0.000000 \\
\hline AFER & & & & & & $0.0049 \%$ \\
\hline MSE & & & & & 4.2857 & \\
\hline
\end{tabular}

Note. In TABLE II: MSE (Mean Square Error): $M S E=\frac{1}{n-1} \sum_{u w=2}^{n}\left(A_{u w}-F_{u w}\right)^{2}$; AFER (Average Forecasting Error Rate): $A F E R=\left(\frac{1}{n-1} \sum_{u w=2}^{n}\left|A_{u w}-F_{u w}\right| / A_{u w}\right) \times 100 \%$.

TABLE II. PARTIAL FORECASTING MODEL OF $\mathrm{F}_{\mathrm{W}}(0.0003,0.0003)$ IS APPLIED TO FORECAST THE ENROLLMENT OF THE UNIVERSITY OF ALABAMA

\begin{tabular}{|c|c|c|c|c|c|c|}
\hline Year & $\begin{array}{c}\text { Enrollment } \\
\mathbf{A}_{\text {uw }}\end{array}$ & $\begin{array}{c}\text { The ordered difference } \\
b_{w}\end{array}$ & $\begin{array}{c}\text { Forecast } \\
\text { Fuw }_{u w}\end{array}$ & $\mathbf{F}_{\mathbf{u w}}-\mathbf{A}_{\mathbf{u w}}$ & $\left(\mathrm{F}_{\mathrm{uw}}-\mathrm{A}_{\mathrm{uw}}\right)^{2}$ & $\left|\mathbf{F}_{\mathbf{u w}}-\mathbf{A}_{\mathbf{u w}}\right| / \mathbf{A}_{\mathbf{u w}}$ \\
\hline 1971 & 13055 & - & - & - & - & - \\
\hline 1972 & 13563 & $\mathrm{~d}_{1}, \mathrm{C}_{1982},-955$ & 13563 & 0 & 0 & 0.000000 \\
\hline 1973 & 13867 & $\mathrm{~d}_{2}, \mathrm{C}_{1981},-531$ & 13867 & 0 & 0 & 0.000000 \\
\hline 1974 & 14696 & $\mathrm{~d}_{3}, \mathrm{C}_{1992},-461$ & 14696 & 0 & 0 & 0.000000 \\
\hline 1975 & 15460 & $\mathrm{~d}_{4}, \mathrm{C}_{1984},-352$ & 15460 & 0 & 0 & 0.000000 \\
\hline 1976 & 15311 & $\mathrm{~d}_{5}, \mathrm{C}_{1976},-149$ & 15310 & 1 & 1 & 0.000065 \\
\hline 1977 & 15603 & $\mathrm{~d}_{6}, \mathrm{C}_{1991}, 9$ & 15603 & 0 & 0 & 0.000000 \\
\hline 1978 & 15861 & $\mathrm{~d}_{7}, \mathrm{C}_{1985}, 18$ & 15861 & 0 & 0 & 0.000000 \\
\hline 1979 & 16807 & $\mathrm{~d}_{8}, \mathrm{C}_{1983}, 64$ & 16807 & 0 & 0 & 0.000000 \\
\hline 1980 & 16919 & $\mathrm{~d}_{9}, \mathrm{C}_{1980}, 112$ & 16919 & 0 & 0 & 0.000000 \\
\hline 1981 & 16388 & $\mathrm{~d}_{10}, \mathrm{C}_{1978}, 258$ & 16388 & 0 & 0 & 0.000000 \\
\hline 1982 & 15433 & $\mathrm{~d}_{11}, \mathrm{C}_{1977}, 292$ & 15433 & 0 & 0 & 0.000000 \\
\hline 1983 & 15497 & $\mathrm{~d}_{12}, \mathrm{C}_{1973}, 304$ & 15497 & 0 & 0 & 0.000000 \\
\hline 1984 & 15145 & $\mathrm{~d}_{13}, \mathrm{C}_{1990}, 358$ & 15145 & 0 & 0 & 0.000000 \\
\hline 1985 & 15163 & $\mathrm{~d}_{14}, \mathrm{C}_{1972}, 508$ & 15163 & 0 & 0 & 0.000000 \\
\hline 1986 & 15984 & $\mathrm{~d}_{15}, \mathrm{C}_{1975}, 764$ & 15984 & 0 & 0 & 0.000000 \\
\hline 1987 & 16859 & $\mathrm{~d}_{16}, \mathrm{C}_{1989}, 820$ & 16859 & 0 & 0 & 0.000000 \\
\hline 1988 & 18150 & $\mathrm{~d}_{17}, \mathrm{C}_{1986}, 821$ & 18150 & 0 & 0 & 0.000000 \\
\hline 1989 & 18970 & $\mathrm{~d}_{18}, \mathrm{C}_{1974}, 829$ & 18970 & 0 & 0 & 0.000000 \\
\hline 1990 & 19328 & $\mathrm{~d}_{19}, \mathrm{C}_{1987}, 875$ & 19328 & 0 & 0 & 0.000000 \\
\hline 1991 & 19337 & $\mathrm{~d}_{20}, \mathrm{C}_{1979}, 946$ & 19337 & 0 & 0 & 0.000000 \\
\hline 1992 & 18876 & $\mathrm{~d}_{21}, \mathrm{C}_{1988}, 1291$ & 18876 & 0 & 0 & 0.000000 \\
\hline AFER & & & & & & $0.0003 \%$ \\
\hline MSE & & & & & 0.0476 & \\
\hline
\end{tabular}


TABLE III. PARTIAL FORECASTING MODEL OF F $F_{W}(0.00003,0.00003)$ IS APPLIED TO FORECAST THE ENROLLMENT OF THE UNIVERSITY OF ALABAMA

\begin{tabular}{|c|c|c|c|c|c|c|}
\hline Year & $\begin{array}{c}\text { Enrollment } \\
\mathbf{A}_{\mathbf{u w}}\end{array}$ & $\begin{array}{l}\text { The ordered difference } \\
b_{w}\end{array}$ & $\begin{array}{c}\text { Forecast } \\
\text { Fuw }_{\text {uw }}\end{array}$ & $\mathbf{F}_{\mathbf{u w}}-\mathbf{A}_{\mathbf{u w}}$ & $\left(\mathbf{F}_{\mathrm{uw}}-\mathbf{A}_{\mathrm{uw}}\right)^{2}$ & $\left|\mathbf{F}_{u w}-\mathbf{A}_{u w}\right| / \mathbf{A}_{u w}$ \\
\hline 1971 & 13055 & - & - & - & - & - \\
\hline 1972 & 13563 & $\mathrm{~d}_{1}, \mathrm{C}_{1982},-955$ & 13563 & 0 & 0 & 0.000000 \\
\hline 1973 & 13867 & $\mathrm{~d}_{2}, \mathrm{C}_{1981},-531$ & 13867 & 0 & 0 & 0.000000 \\
\hline 1974 & 14696 & $\mathrm{~d}_{3}, \mathrm{C}_{1992},-461$ & 14696 & 0 & 0 & 0.000000 \\
\hline 1975 & 15460 & $\mathrm{~d}_{4}, \mathrm{C}_{1984},-352$ & 15460 & 0 & 0 & 0.000000 \\
\hline 1976 & 15311 & $\mathrm{~d}_{5}, \mathrm{C}_{1976},-149$ & 15311 & 0 & 0 & 0.000000 \\
\hline 1977 & 15603 & $\mathrm{~d}_{6}, \mathrm{C}_{1991}, 9$ & 15603 & 0 & 0 & 0.000000 \\
\hline 1978 & 15861 & $\mathrm{~d}_{7}, \mathrm{C}_{1985}, 18$ & 15861 & 0 & 0 & 0.000000 \\
\hline 1979 & 16807 & $\mathrm{~d}_{8}, \mathrm{C}_{1983}, 64$ & 16807 & 0 & 0 & 0.000000 \\
\hline 1980 & 16919 & $\mathrm{~d}_{9}, \mathrm{C}_{1980}, 112$ & 16919 & 0 & 0 & 0.000000 \\
\hline 1981 & 16388 & $\mathrm{~d}_{10}, \mathrm{C}_{1978}, 258$ & 16388 & 0 & 0 & 0.000000 \\
\hline 1982 & 15433 & $\mathrm{~d}_{11}, \mathrm{C}_{1977}, 292$ & 15433 & 0 & 0 & 0.000000 \\
\hline 1983 & 15497 & $\mathrm{~d}_{12}, \mathrm{C}_{1973}, 304$ & 15497 & 0 & 0 & 0.000000 \\
\hline 1984 & 15145 & $\mathrm{~d}_{13}, \mathrm{C}_{1990}, 358$ & 15145 & 0 & 0 & 0.000000 \\
\hline 1985 & 15163 & $\mathrm{~d}_{14}, \mathrm{C}_{1972}, 508$ & 15163 & 0 & 0 & 0.000000 \\
\hline 1986 & 15984 & $\mathrm{~d}_{15}, \mathrm{C}_{1975}, 764$ & 15984 & 0 & 0 & 0.000000 \\
\hline 1987 & 16859 & $\mathrm{~d}_{16}, \mathrm{C}_{1989}, 820$ & 16859 & 0 & 0 & 0.000000 \\
\hline 1988 & 18150 & $\mathrm{~d}_{17}, \mathrm{C}_{1986}, 821$ & 18150 & 0 & 0 & 0.000000 \\
\hline 1989 & 18970 & $\mathrm{~d}_{18}, \mathrm{C}_{1974}, 829$ & 18970 & 0 & 0 & 0.000000 \\
\hline 1990 & 19328 & $\mathrm{~d}_{19}, \mathrm{C}_{1987}, 875$ & 19328 & 0 & 0 & 0.000000 \\
\hline 1991 & 19337 & $\mathrm{~d}_{20}, \mathrm{C}_{1979}, 946$ & 19337 & 0 & 0 & 0.000000 \\
\hline 1992 & 18876 & $\mathrm{~d}_{21}, \mathrm{C}_{1988}, 1291$ & 18876 & 0 & 0 & 0.000000 \\
\hline AFER & & & & & & $0 \%$ \\
\hline MSE & & & & & 0 & \\
\hline
\end{tabular}

\section{ACKNOWLEDGMENT}

This work is supported by Hainan Province Nature Science Foundation Project (Fund number: 714283), the Science and Technology Cooperation Project of the Academy and Government of Sanya (Fund number: 2016YD04, 2015YD33), and Hainan Tropical Ocean University Research Project (Fund number: RDJGb2017-14).

\section{REFERENCES}

[1] G. Udny Yule, "On a Method of Investigating Periodicities in Disturbed Series, with Special Reference to Wolfer's Sunspot Numbers," Philosophical Transactions of the Royal Society. A: Mathematical, Physical and Engineering Sciences, vol. 226, pp. 267-298, 1927.

[2] Q. Song and B. S. Chissom, "Fuzzy series and its models," Fuzzy Sets and Systems. vol. 54, pp. 269-277, 1993.

[3] Q. Song and B. S. Chissom, "Forecasting enrollments with fuzzy time series_Part I," Fuzzy Sets and Systems. vol. 54, pp. 1-9, 1993.

[4] Q. Song and B. S. Chissom, "Forecasting enrollments with fuzzy time series-Part II," Fuzzy Sets and Systems. vol. 62, pp. 1-8, 1994.

[5] L. A. Zadeh, "Fuzzy set," Fuzzy Sets and Systems. vol. 8, pp. 338-353, 1965.

[6] Tahseen A. Jilani, S. M. Aqil Burney, and C. Ardil, "Multivariate high order fuzzy time series forecasting for car road accidents," World Academy of Science, Engineering and Technology. vol. 1, pp. 288-293, 2007.

[7] Tahseen Ahmed Jilani, Syed Muhammad Aqil Burney, and Cemal Ardil, "Fuzzy Metric Approach for Fuzzy Time Series Forecasting based on Frequency Density Based Partitioning,” World Academy of Science, Engineering and Technology. vol. 34, pp. 1-6, 2007.

[8] Bhagawati P. Joshi and Sanjay Kumar, "A computational method for fuzzy time series forecasting based on difference parameters," International Journal of Modeling, Simulation, and Scientific Computing. vol. 4, No. 1, pp. 1250023-1-1250023-12, 2013.
[9] M. Stevenson and J. Porter, "Fuzzy time series forecasting using percentage change as the universe of discourse," Proceedings of World Academy of Science, Engineering and Technology. vol. 55, pp. 154-157, 2009.

[10] Preetika Saxena, Kalyani Sharma, and Santhosh Easo, "Forecasting enrollments based on fuzzy time series with higher forecast accuracy rate,” Int. J. Computer Technology \& Applications. vol. 3, No. 3, pp. 957-961, 2012.

[11] R. C. Tsaur, J. C. O. Yang, and H. F. Wang, "Fuzzy relation analysis in fuzzy time series model,” Comput. Math. Appl. vol. 49, pp. 539-548, 2005.

[12] T. A. Jilani, S. M. A. Burney, and C. Ardil, “ Multivariate high order fuzzy time series forecasting for car road accidents,” International Journal of Computational Intelligence. vol. 4, No. 1, pp. 15-20, 2007.

[13] S. R. Singh, "A simple method of forecasting based on fuzzy time series,” Appl. Math. Comput. vol. 186, pp. 330-339, 2007.

[14] S. R. Singh, "A robust method of forecasting based on fuzzy time series,” Appl. Math. Comput. vol. 188, pp. 472-484, 2007.

[15] Wang Hongxu and Wu Zhenxing, "Preliminary Theory of Set DR of Fuzzy Time Series Forecasting Model,” 2016 International Conference on Mathematical, Computational and Statistical Sciences and Engineering (MCSSE2016). pp. 256-260, 2016.

[16] Wang Hongxu and Wu Zhenxing, "Preliminary Theory of Set SDR of Fuzzy Time Series Forecasting Model,” 2016 International Conference on Mathematical, Computational and Statistical Sciences and Engineering (MCSSE2016). pp. 261-265, 2016.

[17] Ming Liu, Hongxu Wang, Youming Li, and Xuebing Huang, "Fuzzy Time Series Forecasting Model Based on DRDDR and Application," 2016 2nd International Conference on Electronics, Network and Computer Engineering (ICENCE2016), Advances in Computer Science Research, Part C, ISSN 2352-538X. vol. 67, pp. 574-578, 2016.

[18] Ming Liu, Hongxu Wang, Youming Li, and Xuebing Huang, "Analysis of Proportion of Possession of Tourism Income in Tertiary Industry in Hainan Province based on DDD,” Advances in Economics, Business and Management Research, (IEESASM 2016), Part D, ISSN 2352-538X. vol. 67, pp. 691-694, 2016. 